\title{
Correspondence
}

\section{Efficiency of epidural blood patches in the obstetrics}

To the Editor:

We were very interested to read the North American survey of the management of dural puncture (DP) occurring during labour epidural analgesia. ${ }^{1}$ The authors showed that the optimism regarding the efficacy of epidural blood patch (EBP) was not supported by the evidence available.

We recently audited our practice. Between February 1993 and March 1998, 5,705 epidurals were performed for 14,775 deliveries. There were 55 inadvertent DP $(0.96 \%)$ of which 50 experienced post dural puncture headache (PDPH) within the first 24 hr. Re-siting the epidural catheter was the most common initial response to DP. Simple analgesics with enhanced oral hydration, rest and laxatives were also commonly recommended. Epidural saline was administered less frequently, and in none of our cases were abdominal binders or caffeine infusions used.

Prophylactic EBP was employed in 13\% of cases but was effective in only $29 \%$. The majority of our patients (75\%) received a therapeutic EBP, performed within one day of the diagnosis. The EBP was completely effective in $34 \%$ of cases and, in a further $29 \%$, a second EBP was required and was usually performed within 48-72 $\mathrm{hr}$ of the first. The repeat EBP was effective in only $50 \%$ of patients. Moreover, half were left with persisting symptoms despite having had one or two blood patches and additional conservative measures.

Elisabeth Williams MBBS FRCA

Pierre Beaulieu MD PhD FRCA

Gareth Jenkins MBBS FRCA

William Fawcett MBBS FRCA

Royal Surrey County Hospital

Guildford, United Kingdom

\section{REFERENCE}

1 Berger CW, Crosby ET, Grodecki W. North American survey of the management of dural puncture occurring during labour epidural analgesia. Can J Anaesth 1998; 45: $110-4$.

\section{An "immobile needle" for epidural blood patch}

To the Editor:

I have recently modified my technique when performing epidural blood patches. Location of the epidural space is performed in the usual manner and the blood drawn from the patient's forearm. I then use a low volume intravenous extension tubing to connect the syringe and the Tuohy needle. The tubing is flushed with blood prior to connection to avoid the unnecessary introduction of air into the epidural space. The use of a flexible linkage between needle and syringe permits a more relaxed posture by the anaesthetist, allowing the injection of blood to be unhurried and ensuring the Tuohy needle is motionless. The use of a low volume extension means that no more than $2 \mathrm{ml}$ of blood is lost in the dead space of the tubing. This technique is an adaptation of the "Immobile needle for nerve blocks" as described by Winnie.

Richard A. French MBBS FAnZCA

King Edward Memorial Hospital

Perth, Australia

\section{REFERENCE}

1 Winnie AP. An "Immobile needle" for nerve blocks. Anesthesiology 1969; 31: 577-8.

\section{Fatal pulmonary embolism during limb exanguination}

To the Editor:

Rare cases of massive pulmonary embolism (PE) have been attributed to use of tourniquets during lower extremity surgical procedures. ${ }^{1-5}$ These events occurred during preinflation exanguination manoeuvres 1,2 and after tourniquet inflation ${ }^{4}$ and deflation. ${ }^{5}$

A 76-yr-old woman, with superficial varicose veins, underwent an open reduction and internal fixation of an external femoral condyle fracture one day after injury. Subarachnoid anaesthesia was performed and 
Esmarch ${ }^{\circledR}$ compression bandages were applied from the toes to the groin in preparation for tourniquet ischaemia. At this time, the patient lost consciousness, became apneic and collapsed. Resuscitation procedures were instituted and transoesophageal echocardiography revealed PE. In spite of haemodynamic support and thrombolytic therapy, the patient died.

Post-mortem examination revealed multiple thromboemboli of recent origin in the right heart cavities, in the pulmonary arteries and in popliteal and tibial veins of the injured leg. The pathological mechanism was presumably related to the pressure created by the Esmarch bandage, producing a dislodgement of preexisting thrombi. ${ }^{4}$

The best approach in the prevention of this catastrophic event lies in the early diagnosis and aggressive management of deep venous thromboembolic disease. This woman had three risk factors: age, venous insufficiency and long bone fracture. Preoperative screening using non-invasive diagnostic procedures, such as Doppler ultrasound examination, would be performed. Also, the indication of Esmarch bandage compression before tourniquet inflation in presence of patients at risk of lower limb deep-vein thrombosis needs to be evaluated. This manoeuvre could have been replaced by an elevation of the extremity to produce a relative bloodless fieid.

Jean G. Boogaerts MD PhD

Charleroi University Hospital Centre

Belgium

\section{REPERENCES}

1 Pollard BJ, Lovelock HA, Jones RM. Fatal pulmonary embolism secondary to limb exsanguination. Anesthesiology 1983; 58: 373-4.

2 Sermeus $L_{s}$ Van Hemelrijck J, Vandommele J, Van Aken $H$. Pulmonary embolism confirmed by transoesophageal echocardiography. Anaesthesia 1992; 47: $28-9$.

3 Estrera AS, King RP, Platt MR. Massive pulmonary embolism: a complication of the technique of tourniquet ischemia. J Trauma 1982; 22: 60-2.

4 Hofmann $A A$, Wyatt RWB. Fatal pulmonary embolism following tourniquet inflation. J Bone Joint Surg 1985; 67A: 633-4.

5 McGrath BJ, Hsia J, Epstein B. Massive pulmonary embolism following tourniquet deflation. Anesthesiology 1991; 74: 618-20.

\section{“3-in-1” Femoral block}

To the Editor:

We read with interest the report by Fournier et al. on postoperative analgesia with " 3 -in-1" femoral nerve block after prosthetic hip surgery. ${ }^{1}$ Although the block may be of some help for postoperative analgesia after prosthetic hip surgery, we are concerned with the study design. Performing the block after induction of anaesthesia may be associated with some bias since the obturator provides sensory branches to the hip. Blocking the obturator nerve through a "3-in-l" femoral block may be disappointing. Lang et al. ${ }^{2}$ demonstrated only $4 \%$ successful obturator block after $30 \mathrm{ml}$ of either lidocaine $1 \%$ with $1: 200,000$ epinephrine or bupivacaine $0.375 \%$ with $1.200,000$ epinephrine. Singelyn $e$ t $a l^{3}{ }^{3}$ showed only $40 \%-55 \%$ successful block was obtained after $40 \mathrm{ml}$ bupivacaine $0.25 \%$ followed by a continuous infusion of bupivacaine $0.125 \%$ at $10 \mathrm{ml} \cdot \mathrm{hr}^{-1}$ whether the catheter was inserted $10-15$ $\mathrm{cm}$, or more than $15 \mathrm{~cm}$, respectively. It is difficult to evaluate, in this surgical context, the value of the 3 -in1 block without knowing if the obturator is blocked. Secondly, performing a peripheral block in an anaesthetized patient does not permit recognition of local anaesthetic associated paresthesias or severe pain, both symptoms of possible nerve injury. ${ }^{4}$

The 3-in-1 block controversy still continues ... is it really 4 -in-1 or 2 -in- $1 ?^{5} \mathrm{We}$ believe it will be mandatory in future clinical investigations to determine if the obturator nerve has been blocked. Moreover, we recommend that peripheral blocks not be performed anaesthetized patients, to decrease the incidence of complications associated with regional anaesthesia.

\section{T. Singer $M D$ \\ P. Bird MD \\ A Borgeat MD \\ Zurich, Switzerland}

\section{REFERENCES}

1 Fournier R, Van Gessel E, Gaggero G, Boccovi S, Forster $A$, Gamulin Z. Postoperative analgesia with "3-in- 1" femoral nerve block after prosthetic hip surgery. Can J Anaesth 1998; 45: 34-8.

2 Lang $S A$, Yip RW, Chang PC, Gerard $M A$. The femoral 3-in-1 block revisited. J Clin Anesth 1993; 5: 292-6.

3 Singelyn FJ, Goossens F, Van Roy C, Gourverneur JM. During continuous 3-in-1 block (CB), a high position of the catheter increases the success rate of the tèchnique. Int Monitor 1996; 8: 105.

4 Auroy $\Upsilon$, Narchi P, Messiah A, Litt L, Rouvier B, Samii $K$. Serious complications related to regional anesthesia: results of a prospective survey in France. Anesthesiology 1997; 87: 479-86.

5 Winnie $A P$. The "3-in-1 block": is it really 4 -in-1 or 2in-1? (Letter) Reg Anesth 1992; 17: 176-9. 